\title{
DIFFERENCES IN THE MICROBIAL POPULATION ASSOCIATED WITH THREE WETLAND TYPES IN THE SANJIANG PLAIN, NORTHEAST CHINA
}

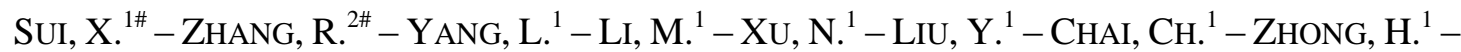 \\ WANG, J. ${ }^{2}-\mathrm{NI}, \mathrm{H}^{1}{ }^{*}-\mathrm{XU}, \mathrm{M}^{1}{ }^{1}-\mathrm{XING}, \mathrm{J}^{1}{ }^{1}-$ WANG, J. ${ }^{1}-\mathrm{LI}, \mathrm{M}{ }^{3}$ \\ ${ }^{1}$ Institute of Nature and Ecology, Heilongjiang Academy of Sciences \\ Harbin 150040, China \\ ${ }^{2}$ Harbin Normal University \\ Harbin 150040, China \\ ${ }^{3}$ Swiss Federal Research Institute WSL, Birmensdorf, Switzerland \\ (phone: +86-0451-86050152; fax: +86-0451-86664613) \\ *Corresponding author \\ e-mail: nihongwei2000@163.com \\ (phone: +86-0451-86053721; fax: +86-0451-86664613) \\ ${ }^{\#}$ these authors contributed equally to this work \\ (Received $4^{\text {th }}$ Jul 2016; accepted 26 $6^{\text {th }}$ Sep 2016)
}

\begin{abstract}
The Sanjiang Plain is the largest freshwater wetland area in Northeast China and plays an important role in regulating climate stability for this region. However, agricultural activity has decreased wetland coverage with about $84 \%$ since the 1950s. This has resulted in lowered water tables and degraded wetlands, with dryer marsh meadows and dry meadow coverage replacing wet marshlands. Here, we report investigations towards the soil microbial community composition and diversity in the different degeneration wetlands types. Bacterial and fungal communities in the soil types were compared using high resolution bar-coded pyrosequencing technology. The results revealed that the bacterial and fungal diversity was lower in wet marshland than in drier marsh meadow and dry meadows. The distribution of sequence reads into different bacterial and fungal phyla further differed between the soil samples. The wet marsh soil displayed a higher abundance of Proteobacteria but lower abundance of Acidobacteria, while the higher abundance of unclassified fungi but smaller fractions of Ascomycota and Basidiomycota than the other soil types.The results reported here demonstrate that soil bacterial and fungal communities change as a result of differences in the soil environment in the Sanjiang Plain.
\end{abstract}

Keywords: community structure, microorganism; Miseq; wetland degradation; bacterial diversity; fungal diversity

\section{Introduction}

Wetlands are the most important terrestrial ecosystems in the world, having crucial environmental functions such as regulation of the carbon cycle (Keller, 2011), maintaining fresh water capacities (McJannet et al., 2012) and protecting biodiversity (Burton and Uzarski, 2009). Wetlands are areas with land and shallow water bodies, where the water tables permanently or periodically higher than surface level and with specific wetland ecological communities (Mausbach and Parker, 2001; Mitsch and Gosselink, 2007). Although natural wetlands occupy only 5-8 \% of Earth's land surfaces (Mitsch and Gosselink, 2007), they are regarded as the "kidney" of the Earth, playing several key roles in biogeochemical processes such as pollutant degradation, 
nitrification, denitrification, methanogenesis, methanotrophy, and iron and sulfate reduction (Davidsson et al., 1997; Gutknecht et al., 2006).

The Sanjiang Plain, covering an area of 10.89 million hectare, contains the largest freshwater wetland in Northeast China. It is also named Deyeuxia angustifolia (Kom.) wetland because this plant is the dominant species in the area.The local wetland environment is inevitable for climate stability, biodiversity protection, and greenhouse gas emission reduction in Northeast Asia. However, growing human populations have resulted in a decline of the wetlands. Whereas half of the Sanjiang Plain was covered by freshwater in 1950 (Zhao et al., 1999; Liu and Ma, 2000), approximately 84\% of the wetlands have since been converted to farmland, especially to paddy fields (Liu and Ma, 2000). As a consequence of agricultural water use and decreased precipitation, the amount of water and water-covered surface area has decreased steadily, resulting in degraded wetlands. The original wet marshlands have changed to drier marsh meadows (recognized as a transitional state in wetland degeneration) and eventually into dry meadows, a fully degenerative state of wetland. Ecosystems have changed as well, with a decreased vegetation diversity, a fall in methane emission and a rise incarbon dioxide and nitrous oxide emission being prominent.

Several studies have evaluated the effects of wetland degeneration in the Sanjiang Plain on greenhouse gas emission (Song et al., 2013), nitrogen cycling between the atmosphere, vegetation and the soil (Sun, 2007), or soil microbial biomass and soil respiration (Huang et al., 2012), but little attention has been paid to the composition and diversity of soil microbial communities and how the microbial composition responses to wetland degeneration. With the complete array available from pristine wetlands to severely degenerative states, including three well-recognized wetland types along a water decline gradient within a small area, the site of the Sanjiang Wetland Experimental Station provided ideal site to study the effects on soil microbial ecosystems.

We hypothesized that changes in the soil microbial communities would be visible between wet marshlands, drier marsh meadows and dry meadows in Sanjiang Plain, and further that the variation in composition of soil fungi might exceed that of bacteria. To test these hypotheses, we collected soil samples from the three wetland types and estimated the composition, diversity and phylogeny of soil bacterial and fungal communities in these samples using high-throughput sequence analysis.

\section{Material and methods}

\section{Site description and soil sampling}

The study was conducted at the Sanjiang Wetland Experimental Station $\left(47^{\circ} 35^{\prime} \mathrm{N}\right.$, $\left.133^{\circ} 31^{\prime} \mathrm{E}\right)$, property of the Institute of Nature and Ecology of Heilongjiang Academy of Sciences, China (Figure 1). The local average monthly temperature ranges from -21.6 ${ }^{\circ} \mathrm{C}$ in January to $21.5^{\circ} \mathrm{C}$ in July, with an annual average of $1.9^{\circ} \mathrm{C}$. The average annual precipitation is about $560 \mathrm{~mm}$, with approximately $80 \%$ occurring between May and October. Three sites inside the station were selected for this study. Wet marshland was designated $\mathrm{K} 0$, a drier marsh meadow as $\mathrm{K} 1$ and dry meadow was called $\mathrm{K} 2$. The $\mathrm{K} 0$ site was approximately $20 \mathrm{~m}$ away from $\mathrm{K} 2$, and these were approximately $1 \mathrm{~km}$ away from the K1 site. All three sites are characterized by Quaternary sediments, and their soils were classified as Albic Boric Luvisols with a silty clay texture (Xi, 1993). 


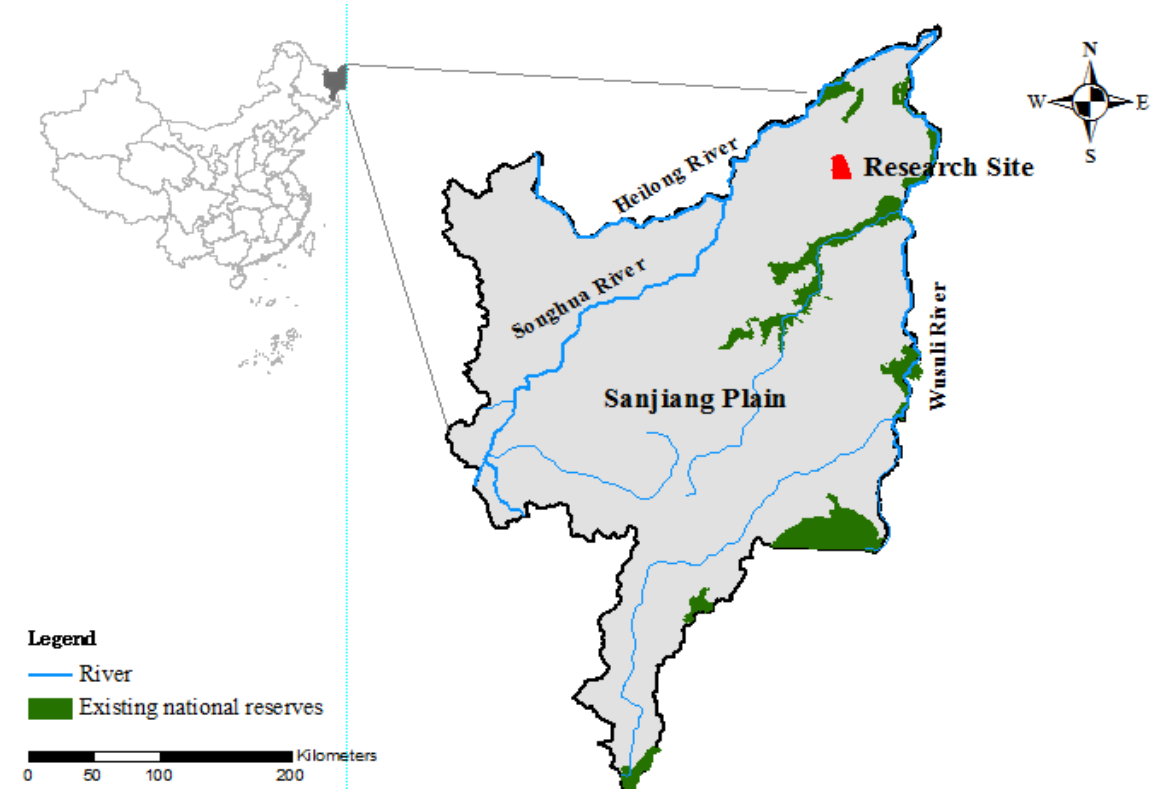

Figure 1. Map of the Research Site in the Sanjiang Plain, China

Soil samples were taken at a depth of 0-20 cm on 15 June 2014. Approximately $1 \mathrm{~kg}$ soil was collected from five locations within each site and stored in polyethylene bags, placed in a container with ice and immediately transported to the laboratory. Upon arrival, approximately $2 \mathrm{~g}$ of each soil sample was placed in a sterile micro centrifuge tube $(2 \mathrm{~mL})$ and stored at $-80{ }^{\circ} \mathrm{C}$ for DNA extraction. The remaining of the samples was air-dried with the weight difference used as a measure of soil water content. Dried soil was used for the determination of other physiochemical properties: Soil $\mathrm{pH}$ was measured using a $\mathrm{pH}$ meter after mixing the soil with water $(1: 5 \mathrm{w} / \mathrm{v})$ for $30 \mathrm{~min}$. The soil total carbon (TC) and total nitrogen (TN) composition was determined using an Elemental analyzer (Vario EL III, Elementar Analyses system, Hanau, Germany). Nitrogen fractions $\mathrm{NH}_{4}{ }^{+}-\mathrm{N}$ and $\mathrm{NO}_{3}{ }^{-}-\mathrm{N}$ were measured by use of FLAstsr 5000 analyzer (Foss Tecator AB Sweden Supply Company, Hoganas, Sweden).

\section{Soil DNA extraction and high-throughput sequencing}

DNA was extracted from $0.5 \mathrm{~g}$ of each frozen soil sample with a MOBIO PowerSoil DNA Isolation Kit (USA) according to the manufacturer's instructions. The extracted DNA was diluted in $100 \mu \mathrm{L}$ TE (10 mM Tris-HCl, $1 \mathrm{mM}$ EDTA, $\mathrm{pH}$ 8.0) and stored at $-20{ }^{\circ} \mathrm{C}$ until used.

For PCR amplification and pyrosequencing we selected the V1-V3 region of bacterial 16S rRNA and the ITS1 region of fungal rDNA (Chakravorty et al., 2007; Bellemain et al., 2010). High-throughput sequencing was performed by the Shanghai Majorbio Biotechnology Company, Shanghai, China.

\section{Data analysis}

Obtained high-throughput sequences were analysed by using Mothur Software. The UniFrac statistical analysis tool was used to compare bacterial and fungal community compositions (Lozupone and Knight, 2005). 


\section{Statistical analysis of effective and optimized gene sequences}

Using the simultaneous sequencing method for multi-samples, a barcode labeled gene sequences and forward primer sequences were introduced in the sequences of all samples. Sequences containing both barcode and forward primer sequences were then selected as effective sequences, after which the sequencing connectors and barcode sequences were removed. Subsequent data analyses were performed using the treated, effective sequences.

To obtain high-quality, accurate results from bio-informatic analyses, sequences were optimized by discarding sequences with lengths less than $150 \mathrm{bp}$, those containing imprecise base calling, or those for which primer bases contained more than two mismatching sequences. The optimized sequences were used for subsequent statistical analyses.

\section{OTU-based analysis}

All sequences were identified to operational taxonomic units (OTU) for bioinformatic statistical analysis. Optimized gene sequences with gene lengths greater than $350 \mathrm{bp}$ were selected, compared with the SILVA database and then clustered. Clustering analysis was performed using the software packages mothur and chopseq (http://www.mothur.org/wiki/Main_Page).

\section{Bacterial community diversity and rarefaction curve}

Species richness and diversity of the bacterial community were characterized by Chaol and the Shannon index, and the sequencing depth index was expressed as Coverage. Alpha-diversity of the bacterial community was measured at significance levels of $97 \%$ (0.03).The estimates were calculated by employing the tools Aligner, Complete Linkage Clustering, and Rarefaction of the RDP pyrosequencing pipeline.

The optimized gene sequences were randomly sampled. The sub-sampled sequences and the number of OTUs present in each were used to calculate a rarefaction curve. If the rarefaction curve tends to be flat then the sampling process is considered to be rational and further sampling is likely to produce few new OTUs, otherwise increased sampling will produce more new OTUs.

\section{Analysis on whole-sample similarity}

The Jest algorithm was used to compare the differences in OTUs from the three soil samples and to calculate the number of sequences from each OTU, thus obtaining a similarity relation between the samples. The selected OTUs had a similarity level of 0.03. Canonical Correlation Analysis for bacteria was conducted by R software.

\section{Results}

\section{Soil Physicochemical Properties}

Soil characteristics such as $\mathrm{pH}$, organic carbon content,total nitrogen,ammonium nitrogen, nitrate nitrogen, and soil water content of the three wetland types $\mathrm{K} 0$ (wet marshland), K1 (drier marsh meadow) and K2 (dry meadow) are listed in Table 1. All but one determined variables followed an increasing trend, from $\mathrm{K} 0$ to $\mathrm{K} 2$, while, as expected, soil water contentwas lower in $\mathrm{K} 2$ than in $\mathrm{K} 0$. 
Table 1. chemical properties of soil samples

\begin{tabular}{ccccccc}
\hline Sites & pH & $\begin{array}{c}\text { Organic } \\
\text { C(g.kg-1) }\end{array}$ & Total N (g.kg-1) $\begin{array}{c}\text { Ammonium } \\
\text { nitrogen(mg.kg-1) }\end{array}$ & $\begin{array}{c}\text { Nitrate } \\
\text { nitrogen } \\
\text { (mg.kg-1) }\end{array}$ & $\begin{array}{c}\text { Soil water } \\
\text { content (\%) }\end{array}$ \\
\hline $\mathrm{K} 0$ & $5.56 \pm 0.01^{\mathrm{A}}$ & $42.32 \pm 0.12^{\mathrm{A}}$ & $2.27 \pm 0.01^{\mathrm{A}}$ & $17.47 \pm 0.56^{\mathrm{A}}$ & $4.25 \pm 0.07^{\mathrm{A}}$ & $185 \pm 0.11^{\mathrm{C}}$ \\
$\mathrm{K} 1$ & $5.66 \pm 0.02^{\mathrm{B}}$ & $44.23 \pm 0.19^{\mathrm{B}}$ & $2.70 \pm 0.02^{\mathrm{B}}$ & $18.51 \pm 0.56^{\mathrm{B}}$ & $4.41 \pm 0.08^{\mathrm{B}}$ & $86 \pm 0.08^{\mathrm{A}}$ \\
$\mathrm{K} 2$ & $5.82 \pm 0.01^{\mathrm{C}}$ & $47.91 \pm 0.16^{\mathrm{C}}$ & $2.88 \pm 0.02^{\mathrm{C}}$ & $20.17 \pm 0.56^{\mathrm{C}}$ & $5.15 \pm 0.05^{\mathrm{C}}$ & $75 \pm 0.10^{\mathrm{A}}$ \\
\hline
\end{tabular}

Different capital letters in the same column identify significant differences at 0.05 level among parameters. K0, K1, K2 represent wet marshland, drier marsh meadow and dry meadow, respectively.

\section{Diversity of bacterial and fungal communities}

The diversity of bacterial and fungal communities was calculated from 16S rRNA sequences and ITS rDNA sequencesat the $3 \%$ level, respectively, among the three samples. In total 660, 683, and 636 OTUs for bacteria and 199, 291, and 260 OTUs for fungi were identified in samples $\mathrm{K} 0, \mathrm{~K} 1$ and $\mathrm{K} 2$, respectively (Table 2). The diversity indices showed that the drier marsh meadow K1 had the highest Shannon's diversity index and the lowest Simpson's index compared with the other samples. The $\mathrm{S}_{\text {chao }}$ estimator of the three samples was in the order $\mathrm{K} 1>\mathrm{K} 2>\mathrm{K} 0$. Thus, all diversity indices showed that the bacterial and fungal community compositions varied between the three types in that they were most diverse in drier marsh meadow soil (Table 2).

\section{Rarefaction curves of bacterial and fungal sequences}

Rarefaction curves were calculated by plotting the number of OTUs at the $3 \%$ level (Figure 2). At that level, the curves were increased at the rate of OTUs detection, indicating that the reads analysis evaluated almost the full extent of taxonomic diversity at the species level, and the coverage of the reads of bacterial and fungal sequences was estimated as above $98 \%$ (Table 2). 
Table 2. Diversity indices for obtained bacterial and fungal sequences from three wetland soils in Sanjiang plain, NE China.

\begin{tabular}{|c|c|c|c|c|c|c|c|c|c|c|c|c|}
\hline & \multicolumn{6}{|c|}{ Bacteria } & \multicolumn{6}{|c|}{ Fungi } \\
\hline & Reads & OTUs & $\begin{array}{c}\text { Coverage } \\
(\%)\end{array}$ & $H^{\prime}$ & $D$ & $S_{\text {chao }}$ & Reads & OTUs & $\begin{array}{c}\text { Coverage } \\
(\%)\end{array}$ & $H^{\prime}$ & $D$ & $S_{\text {chao }}$ \\
\hline $\begin{array}{l}\text { Wet marsh } \\
\text { wetland(K0) }\end{array}$ & 17417 & 660 & $99 \%$ & 5.19 & 0.0156 & 709 & 18375 & 199 & $99.8 \%$ & 2.33 & 0.0920 & 206 \\
\hline $\begin{array}{l}\text { Drier marsh meadow } \\
\text { wetland (K1) }\end{array}$ & 10816 & 683 & $98 \%$ & 5.26 & 0.0129 & 750 & 18299 & 291 & $99.8 \%$ & 3.25 & 0.0782 & 301 \\
\hline $\begin{array}{l}\text { Dry meadow wetland } \\
(\mathrm{K} 2)\end{array}$ & 8955 & 636 & $98 \%$ & 5.22 & 0.0131 & 745 & 22953 & 260 & $99.8 \%$ & 3.49 & 0.0762 & 268 \\
\hline
\end{tabular}

OTUs:Operational taxonomic units, $H^{\prime}$ : Shannon's diversity index, D:Simpson'sindex 


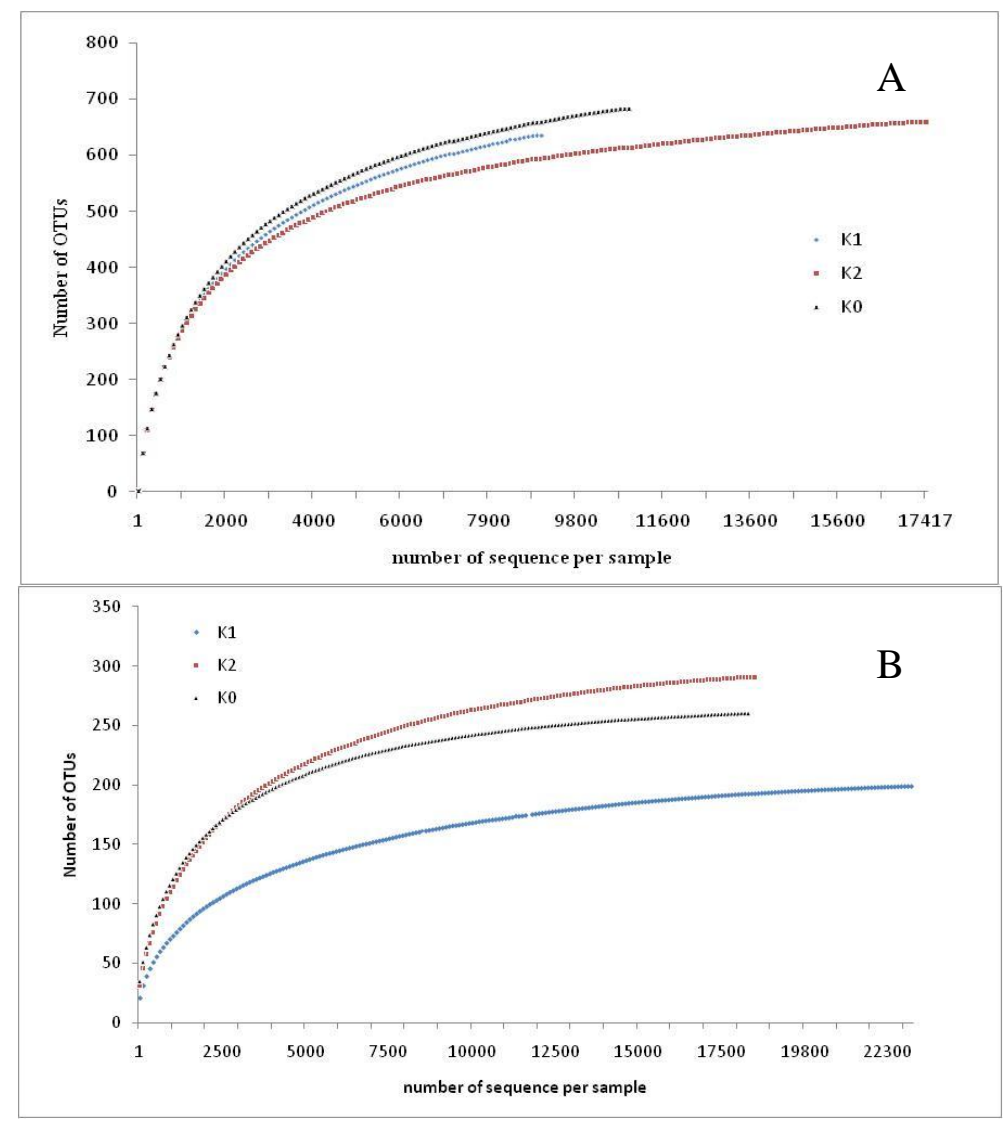

Figure 2. Rarefaction curves for the bacterial 16S (panel A) and fungal ITS (panel B) rRNA sequences obtained. Operational taxonomic units(OTUs) were calculated based on the $3 \%$ level.

\section{Compositions of bacterial and fungal communities}

Bacterial phyla were determined using the classifier tool at the RDP website. The obtained sequences were classified into (in decreasing order):15432 Proteobacteria, 12118 Acidobacteria, 1984 Bacteroidetes, 1533 Chloroflexi, 1530 Planctomycetes, 924 Firmicutes, 899 Nitrospirae, 471 Chlorobi, 332 Gemmatimonadetes and 150 Elusimicrobia; 933 clones remained unclassified. About $90 \%$ of all 37, 188 bacterial clones belonged to six taxonomic phyla: Proteobacteria (42\%), Acidobacteria (33\%), Bacteroidetes (5\%), Chloroflexi (4\%), Planctomycetes(4\%), Firmicutes(3\%) and Nitrospirae $(2 \%)$.

The distribution of clones into the different bacterial divisions among the three high through put clone libraries was uneven, as shown in Figure 3A. Notably, Proteobacteria were highly over represented in wet marshland, while the abundance of Acidobacteria, Chloroflexi and Chlorobiwas higher in the drier marsh meadow soil (K1) than in the other two types. In contrast, Planctomycetes, Nitrospirae and Gemmatimonadetes were more abundant in dry meadow soil K2 in comparison to the other two types. Highest proportions of Bacteroidetes, Firmicutes and unidentified bacteria were observed in wet marshland (K0).

Fungal sequences were divided into 19470 Ascomycota, 23384 Basidiomycota, and these were again unevenly distributed among the three sample types (Figure 3B). The abundance of Ascomycota(56.56\%) and Zygomycota(72.65\%) was higher in the drier 
marsh meadow soils(K1) than in the other two types, while Basidiomycota were remarkably abundant in dry meadow samples(K2), and the highest proportion of unidentified fungal sequences $(75.12 \%)$ was obtained from wetmarshland (K0). Thus, the dominant fungal phylum was different in each type of wetland.

A
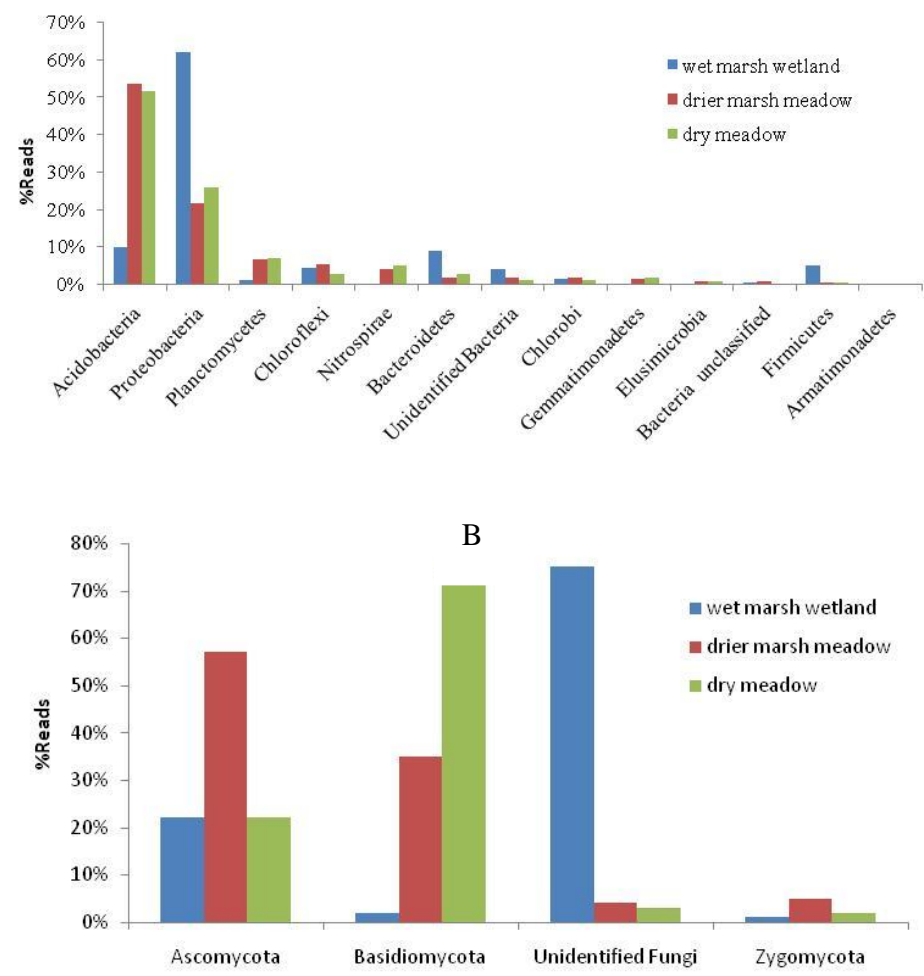

Figure 3. Distribution of thebacterial (panel A) and fungal(panel B) rRNA genesequences in phyla obtained fromwetmarsh wetland (KO), drier marsh meadow wetland (K1) and dry meadow wetland $(K 2)$

\section{Comparison of bacterial and fungal community composition betweenthe three wetlands}

Shared OTUs of bacteria and fungi among the three wetlands are shown in a Venn diagram in Figure 4. The analysis identified that 52 fungal and 373 bacterial OTUs were shared among all three wetland samples, while 41 OTUs of fungi and 178 OTUs of bacteria were shared between drier marsh meadow and dry meadow samples, 34 fungal and 82 bacterial OTUs were found in both wet marshland and drier marsh meadows, and 25 fungal and 48 bacterial OTUs were shared between wet marshland and dry meadow soils. Numbers of unique OTUs were highest in wet marshland K0, both for bacteria (180) and fungi (157), and lowest in dry meadow K2 (81 and 37, respectively). 


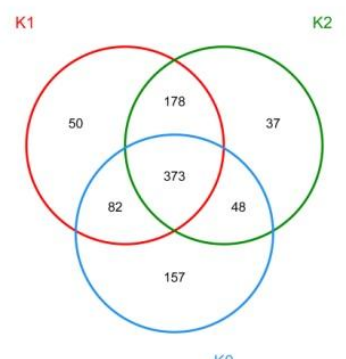

Bacteria

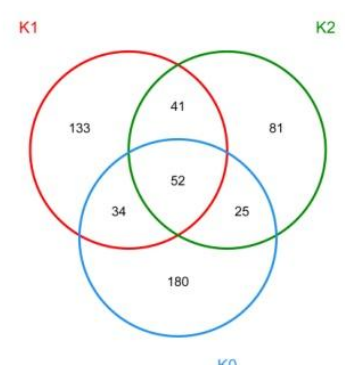

Fungi

Figure 4. Venn diagram showing shared and unique OTUs identified for bacteria (left) and fungi (right) obtained from wet marsh wetland (KO),drier marsh meadow (K1) and dry meadow soils

(K2).

\section{Long-term wetland degeneration alters soil microbial community composition}

The statistical significance of differences in bacterial and fungal community compositions for all sequences was analysed by UniFrac (Table 3). The difference between total clones obtained from $\mathrm{K} 0$ and $\mathrm{K} 1$ was highly significant for bacteria. Highly significant differences at the phyla level are indicated in bold in the table. Only one difference was highly significant for Fungi (Agaricomycetes between K0 and K2).

Finally, a Canonical Correlation Analysis was performed, the results of which are presented in Figure 5. A negative correlation was observed between abundance of Acidobacteria and $\mathrm{pH}$ and soil organic carbon content. Thus, soil $\mathrm{pH}$ and carbon content are the major factors governing the abundance of Acidobacteria in the wetlands of Sanjiang Plain.

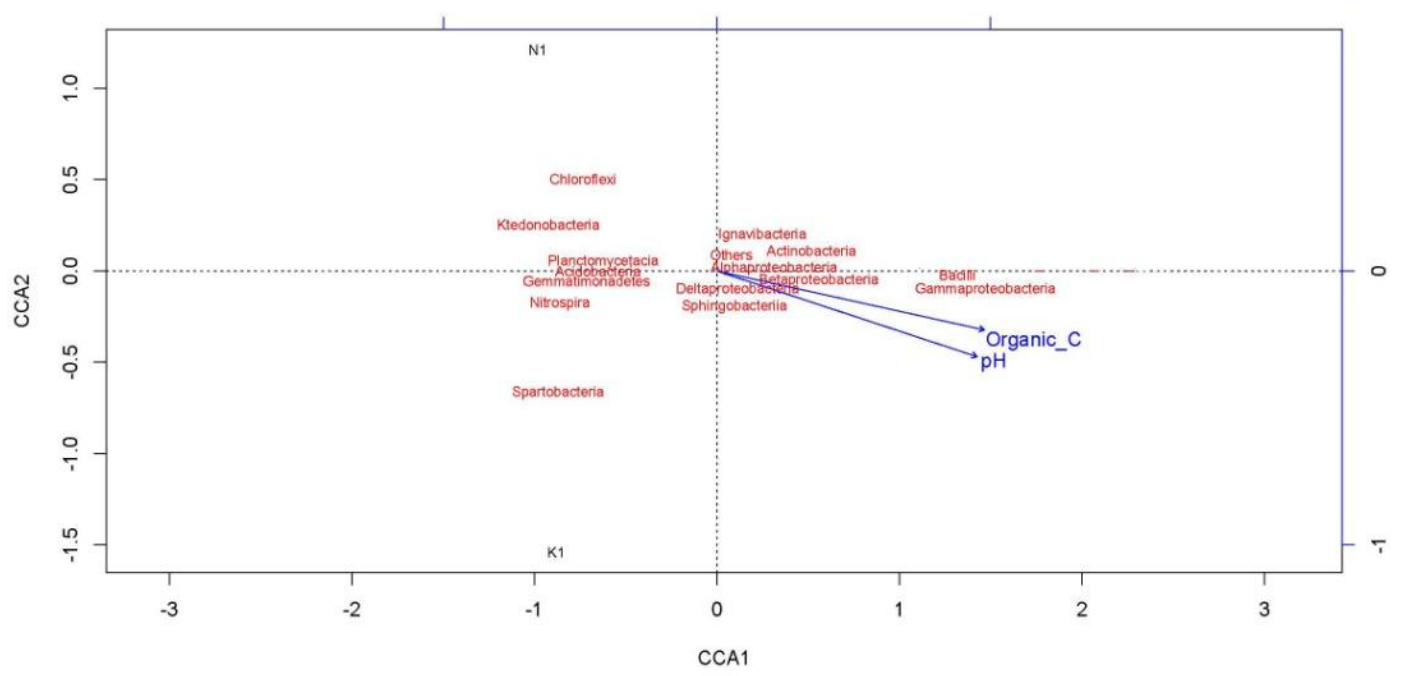

Figure 5. Canonical Correlation Analysis for bacteria in Sanjiang Plain 
Table 3. UniFrac P-test values for bacterial and fungal sequences at total clones and individual phylum level for the three wetland soils in the Sanjiang Plain, NE China

\begin{tabular}{|c|c|c|c|c|c|c|c|c|c|c|c|c|}
\hline \multicolumn{13}{|c|}{ Bacteria } \\
\hline \multirow[t]{2}{*}{ Sample } & \multicolumn{2}{|c|}{ Total clones } & \multicolumn{2}{|c|}{ Acidobacteria } & \multicolumn{2}{|c|}{$\begin{array}{c}\text { Alpha- } \\
\text { proteobacteria }\end{array}$} & \multicolumn{2}{|c|}{ Planctomycetacia } & \multicolumn{2}{|c|}{$\begin{array}{c}\text { Delta- } \\
\text { proteobacteria }\end{array}$} & \multicolumn{2}{|c|}{$\begin{array}{c}\text { Beta- } \\
\text { proteobacteria }\end{array}$} \\
\hline & $\mathrm{K} 1$ & K0 & $\mathrm{K} 1$ & K0 & $\mathrm{K} 1$ & K0 & $\mathrm{K} 1$ & K0 & $\mathrm{K} 1$ & K0 & $\mathrm{K} 1$ & K0 \\
\hline $\mathrm{K} 1$ & - & 0.001 & - & 0.007 & - & 0.001 & - & 0.010 & - & 0.003 & - & 0.022 \\
\hline $\mathrm{K} 2$ & 0.313 & 0.012 & 0.461 & 0.002 & 0.532 & 0.002 & 0.767 & 0.031 & 0.695 & 0.004 & 0.632 & 0.017 \\
\hline \multicolumn{13}{|c|}{ Fungi } \\
\hline \multirow[t]{2}{*}{ Sample } & \multicolumn{2}{|c|}{ Total clones } & \multicolumn{2}{|c|}{ Dothideomycetes } & \multicolumn{2}{|c|}{ Sordariomycetes } & \multicolumn{2}{|c|}{ Agaricomycetes } & \multicolumn{2}{|c|}{ Leotiomycetes } & \multicolumn{2}{|c|}{ Zygomycota } \\
\hline & $\mathrm{K} 1$ & K0 & $\mathrm{K} 1$ & K0 & K1 & K0 & $\mathrm{K} 1$ & K0 & $\mathrm{K} 1$ & K0 & $\mathrm{K} 1$ & K0 \\
\hline $\mathrm{K} 1$ & - & 0.823 & - & 0.415 & - & 0.151 & - & 0.069 & - & 0.812 & - & 0.620 \\
\hline $\mathrm{K} 2$ & 0.779 & 0.996 & 0.047 & 0.095 & 0.322 & 0.537 & 0.162 & 0.005 & 0.274 & 0.237 & 0.447 & 0.339 \\
\hline
\end{tabular}

Statistically significant findings at or below the 0.005 level are given in bold. 


\section{Discussion}

The diversity of bacterial and fungal communities as determined in this study was lower in samples from wet marshland than in the degraded wetland types, as estimated by the number of OTUs, and as indicted by the Shannon's diversity, Simpson's and $S_{\text {chao }}$ indices at phylum level (Table 2).This suggests that during the process of marsh degenerating into dry meadow the diversity of soil bacteria and fungi increases. Marsh wetland is characterized by perennial water levels that are characteristically low in oxygen. This restricts the growth of soil microbes and limits microbial diversity. Drier marsh meadow and dry meadows, however, provide better conditions for a diversity of microbes because their soils have lower water content and much more oxygen, which promoted soil microbial diversity. This is consistent with the results of $\mathrm{Li}$ (2011), who found that increased water content in wetlands decreased the oxygen amount and restrained the growth of fungi. Xu (2004) also found that a high soil water content restrains fungal diversity of valleys wetlands in Changbai Mountains, China ( $\mathrm{Xu}$ et al., 2004). The results presented here also suggest that soil microbial diversity increases as a result of degeneration of wetlands in the Sanjiang Plain.

The difference in bacterial and fungal community compositions between the three wetland types was shown in Fig. 1, and their statistical significance presented in Table 3 , suggest that the degeneration from marsh wetlands todrier environments significantly alters the soil bacterial and fungal community compositions. Liu (2014) also observed changes in the bacterial composition between such environments. Several studies have been conducted on soil microbial composition of various kinds of wetlands around the world (Dedysh, 2011). The majority of available research demonstrated that the proportion of Acidobacteria and Proteobacteria was higher than any other bacterial phyla in wetlands (Hartman et al., 2008; Ausec et al., 2009; Pankratov et al., 2011). For example, Ausec et al. (2009) observed Acidobacteria as the dominant phylum present in bog soils (41.6\%) and in fen soils (23.7\%) sampled in Slovenia. Hartmanet al.(2008) determined 38.1\% Acidobacteria, 17.4\% Alpha proteobacteria and 9.7\% Actinobacteria as the major bacterial phyla in wetland soils of a North Carolina coastal plain, but they did not detect any Chloroflexi (Hartmanet al., 2008). Kanokratana et al. (2011) found that Acidobacteria (35.0\%) and Proteobacteria (37.9\%) dominated in soil from a tropical peat swamp forest in Thailand, by analyzing 280 clones of full length 16s rRNA sequences. The result of our research is consistent with those studies, as we found about 90\% of all bacterial clones belonged to six taxonomic phyla, of which Proteobacteria dominated (Figure 3). The proportion of Proteobacteria was higher in the wet marshland than in the degraded types, but the fraction of Acidobacteria was higher in the two dryer types. This indicates that the composition of bacteria has changed during wetland degeneration. Li (2015) pointed out that Proteobacteria was the dominant phyla in the wetland of the Wuliangsuhai eutrophic lake, with an even higher fraction of Proteobacteria detected than in our findings ( $\mathrm{Li}$ et al., 2015). Proteobacteria seem to dominatein water-covered surfaces but their numbers decrease while Acidobacteria increase during transition to drier environments. The results presented here strongly suggest that the composition of bacterial communities in the three wetland types of the Sanjiang Plain have under gone changes due to a fall of the water table.

The composition of the fungal community seems to be less complex than that of bacteria. The proportions of the three fungal phyla Ascomycota, Basidiomycota, and 
Zygomycota as well as unclassified fungi all varied in the three analysed wetland types. The dominant fungi in the types differed, from unclassified fungi in the wet marshland to Ascomycota in the drier marsh meadow and Basidiomycota in the dry meadow samples.

We thus infer that: 1) the soil nutrients in the three wetland types are different. For example, the wet marshland soil had the highest water content, which combined with low oxygen levels does not support fungal growth very well. This would explain the low fungal diversity and relatively large fraction of unclassified fungi observed. In contrast, a lower soil water content and higher oxygen levels in the drier marsh meadow and dry meadow sites better supported fungal growth and stimulated fungal diversity. 2) The composition of dominant vegetation correlated with the soil fungal composition. Wang (2016, unpublished) observed that with the decrease of the wetland area of the Sanjiang Plain the composition of plants significantly changed due to agricultural development and other human activities. Although Deyeuxia angustifolia was the dominant species in all sampled environments, its proportion was different for each type. As a result, the vegetative was the composition and decomposition ratio differed as well. For example, the litter composition was relatively simple and decomposed rather slowly in the marsh wetland. This correlated with a simple fungal composition and low diversity. The drier marsh meadow and dry meadow lands had a better soil environment to promote higher plant diversity, with a more complex litter composition that decomposed faster, correlating with a fungal composition dominated by Ascomycota and Basidiomycota. Tang (2012) found that soil microbial community compositions change according to water logging time, plant diversity and altitude. Zhao (2011) inferred that soil microbial community compositions were different in different plant diversity wetlands. Nevertheless, other studies reported that plant communities, waste composition and soil nutrients did not affect the compositionof soil microbial communities (Tscherko, 2005; Andersen, 2010). Hence, the underlying causes for variation of soil microbial community composition can becomplex and would require more research to be explained.

As reported by others, the abundance of Acidobacteria correlated negatively with soil organic carbon levels (Smit et al., 2001; Fiereret al., 2007) and soil pH (Jones et al., 2009; Rousk et al., 2010); the Canonical Correlation Analysis presented here also suggest this negative correlation. Thus soil $\mathrm{pH}$ and soil carbon are major factors governing the abundance of Acidobacteria in the wetlands of the Sanjiang Plain.

In conclusion, the conversion from wet marshlands to dry meadow increased the diversity of bacterial and fungal community and altered the community composition. The permanent conversion of submerged marsh wetland into dry meadow increased the abundance of Acidobacteria, Planctomycetes, Ascomycota, and Basidiomycota but decreased the abundance of Proteobacteria and unclassified fungi. These changes correlated with soil $\mathrm{pH}$ and organic carbon content, which were considered main impact factor on soil microbial composition.

Acknowledgements. This research was supported by the National Natural Science Foundation (NO. 31470019, 31400429, 31570485), Fund of Heilongjiang academy of sciences (STJB16-01, STJB16-07, ZR201307, STJB2015-07), Post-doc Fund of Heilongjiang Province and Special project of subject team innovation ability enhancement, Heilongjiang academy of sciences (2014ST05). 


\section{REFERENCES}

[1] Andersen, R., Grasset, L., Thormann, M. N., et al. (2010): Changes in microbial community structure and function following Sphagnum peatland restoration. - Soil Biology and Biochemistry 42(2): 291-301.

[2] Ausec, L., Kraigher, B., Mandic-Mulec, I. (2009): Differences in the activity and bacterial community structure of drained grassland and forest peat soil. - Soil Biology \& Biochemistry 41(9): 1874-1881.

[3] Bellemain, E., Carlsen, T., Brochmann, C., et al.(2010): ITS as an environmental DNA barcode for fungi: an in silico approach reveals potential PCR biases - BMC Microbiology 10(1): 1-9.

[4] Burton, T. M., Uzarski, D. G.(2009): Biodiversity in protected coastal wetlands along the west coast of Lake Huron. - Aquatic Ecosystem Health \& Management 12(1): 63-76.

[5] Chakravorty, S., Helb, D., Burday M, et al. (2007): A detailed analysis of 16S ribosomal RNA gene segments for the diagnosis of pathogenic bacteria - Journal of Microbiological Methods 69(2): 330-9.

[6] Davidsson, T. E, Stepanauskas, R., Leonardson, L. (1997): Vertical Patterns of Nitrogen Transformations during Infiltration in Two Wetland Soils. - Applied \& Environmental Microbiology 63(9): 3648-56.

[7] Dedysh, S. N. (2010): Cultivating Uncultured Bacteria from Northern Wetlands: Knowledge Gained and Remaining Gaps. - Frontiers in Microbiology 2(1): 184.

[8] Gutknecht, J. L. M., Goodman, R. M., Balser, T. C.(2006): Linking soil process and microbial ecology in freshwater wetland ecosystems - Plant \& Soil 289(1): 17-34.

[9] Hartman, W. H, Richardson, C. J, Vilgalys, R., Bruland, G. L. (2008) Environmental and anthropogenic controls over bacterial communitiesin wetland soils. - Proceedings of the National Academy of Sciences 105: 17842-17847.

[10] Huang, G., Cao, Y. F., Wang, B., et al. (2015): Effects of nitrogen addition on soil microbes and their implications for soil $\mathrm{C}$ emission in the Gurbantunggut Desert, center of the Eurasian Continent. - Science of the Total Environment s515-516: 215-224.

[11] Jingyu, H., Changchun, S., Philip, N. N. (2012): Effects of wetland recovery on soil labile carbon and nitrogen in the Sanjiang Plain. - Environmental Monitoring \& Assessment, 185(7):5861-5871.

[12] Jones, R. T., Robeson, M. S., Lauber, C. L., et al. (2009): A comprehensive survey of soil acidobacterial diversity using pyrosequencing and clone library analyses. - Isme Journal 3(4): 442-453.

[13] Kanokratana, P., Uengwetwanit, T., Rattanachomsri, U. (2011): Insights into the Phylogeny and Metabolic Potential of a Primary Tropical Peat Swamp Forest Microbial Community by Metagenomic Analysis. - Microbial Ecology 61(3): 518-528.

[14] Keller, J. K. (2011): Wetlands and the global carbon cycle: what might the simulated past tell us about the future?. - New Phytologist 192(4): 789-792.

[15] Li, J., Du, R., Zhao, J. (2015): High-throughput analysis of bacterial community of transition zone in littoral wetland of Wuliangsuhai eutrophic lake. - Acta Microbiologica Sinica 55(5): 598-606.

[16] Li, Y., Wang, L., Zhang, W., et al. (2011): The variability of soil microbial community composition of different types of tidal wetland in ChongmingDongtan and its effect on soil microbial respiration. - Ecological Engineering 37(9): 1276-1282.

[17] Liu, J., Zheng, C., Song, C., et al. (2014): Conversion from natural wetlands to paddy field alters the composition of soil bacterial communities in Sanjiang Plain, Northeast China. - Annals of Microbiology 64(3): 1395-1403.

[18] Liu, X. T, Ma, X. H. (2000): Influence of Large-Scale Reclamation on Natural Environment and Regional Environmental Protection in the Sanjiang Plain. - Scientia Geographica Sinica, 20(1):14-19 
[19] Mausbach, M. J., Parker, W. B. (2001): Background and history of the concept of hydric soils. - In: Richardson, J. L.,Vepraskas, M. J. (ed.) Wetland soils. Lewis, New York.

[20] Mcjannet, D., Wallace, J., Keen, R., et al. (2012): The filtering capacity of a tropical riverine wetland: I. Water balance. - Hydrological Processes 26(1): 40-52.

[21] Mitsch, W. J, Gosselink, J. G.(2007): Wetlands. - Hoboken, New Jersey.

[22] Noah, F., Bradford, M. A., Jackson, R. B. (2007): Toward an ecological classification of soil bacteria - Ecology 88(6):1354-64.

[23] Pankratov, T. A, Ivanova, A.O, Dedysh, S. N, Liesack, W. (2011): Bacterial populations and environmental factors controlling cellulose degradationin an acidic Sphagnum peat. Environmental Microbiology 13: 1800-1814.

[24] Rousk. J., Bååth, E., Brookes, P. C., et al. (2010): Soil bacterial and fungal communities across a pH gradient in an arable soil - Isme Journal 4(10): 1340-1351.

[25] Smit, E., Leeflang, P., Gommans, S. d. B. J., et al. (2001): Diversity and seasonal fluctuations of the dominant members of thebacterial soil community in a wheat field as determined by cultivation andmolecular methods. - Applied \& Environmental Microbiology 67(5): 2284-2291.

[26] Song, C., Wang, L., Tian, H., et al. (2013): Effect of continued nitrogen enrichment on greenhouse gas emissions from a wetland ecosystem in the Sanjiang Plain, Northeast China: A 5 year nitrogen addition experiment. - Journal of Geophysical Research Biogeosciences 118(2):741-751.

[27] Sun, Z. G, Liu, J. S. (2007): Nitrogen cycling of atmosphere-plant-soil system in the typical Calamagrostisangustifolia wetland in the Sanjiang Plain, Northeast China. Journal of Environmental Sciences 19(8): 986-95.

[28] Tang, J., Ding, X., Wang, L., et al. (2012): Effects of wetland degradation on bacterial community in the Zoige Wetland of Qinghai-Tibetan Plateau (China). - World Journal of Microbiology \& Biotechnology 28(2): 649-657.

[29] Tscherko, D., Hammesfahr, U., Zeltner, G., et al. (2005): Plant succession and rhizosphere microbial communities in a recently deglaciated alpine terrain. - Basic \& Applied Ecology 6(4):367-383.

[30] Wang, J. F, Han, D. Y, Wang J. B, et al. (2016) Variations in plant species composition and diversity of Calamagrostisangustifolia community along soil water level gradient in the SanjiangPlain - Acta Ecologica Sinica (unpublished)

[31] Xi, C. P. (1993): Chinese Soil Taxonomy.

[32] Xu, H. F., Liu, X. T., Bai, J. H. (2004): Dynamic Change and Environmental Effects of Soil Microorganism in Marsh Soils from CarexMeyeriana Wetlands in Changbai Mountain. - Journal of Soil Water Conservation 18(3): 115-122.

[33] Zhao, K.Y. (1999): Mires in China. - Science Press, Beijing.

[34] Zhao, Q. J. (2011): Study on the Soil Microbial Diversity in the Running Constructed Wetland Cultivated with Four Plants. - Journal of Shanghai Jiaotong University 29(3):47-52. 